DOI: 10.17516/1997-1397-2021-14-5-599-603

УДК 517.5

\title{
On the Zeta-Function of Zeros of an Entire Function
}

\author{
Vyacheslav I. Kuzovatov* \\ Alexander M. Kytmanov ${ }^{\dagger}$ \\ Siberian Federal University \\ Krasnoyarsk, Russian Federation \\ Azimbai Sadullaev $\ddagger$ \\ National University of Uzbekistan \\ Tashkent, Uzbekistan
}

Received 10.04.2021, received in revised form 02.06.2021, accepted 20.06.2021

\begin{abstract}
This article is devoted to the study of the properties of the zeta-function of zeros of an entire function. We obtain an explicit expression for the kernel of the integral representation of the zeta-function in one case.
\end{abstract}

Keywords: zeta-function of zeros, integral representation, canonical product.

Citation: V.I. Kuzovatov, A.M. Kytmanov, A.Sadullaev, On the Zeta-Function of Zeros of an Entire Function, J. Sib. Fed. Univ. Math. Phys., 2021, 14(5), 599-603.

DOI: 10.17516/1997-1397-2021-14-5-599-603.

\section{Introduction}

The purpose of this article is to correct a mistake in the work [1]. Namely, in the article [1] an incorrect statement was given that for an entire function $f$, satisfying some additional conditions, the following equality holds on the positive part of the real axis

$$
\frac{f^{\prime}(x)}{f(x)}=\frac{\sqrt{\pi}}{2 \sqrt{x}}-\frac{1}{2 x} .
$$

It is easy to see that for any entire function $f$ this equality cannot be true on the whole positive semiaxis. Indeed, the function $\frac{f^{\prime}(z)}{f(z)}$ is meromorphic in the whole complex plane. By virtue of the uniqueness theorem, the equality (1) holds not only on $\mathbb{R}^{+}$, but also in $\mathbb{C} \backslash\{0\}$. However, the function

$$
\frac{\sqrt{\pi}}{2 \sqrt{z}}-\frac{1}{2 z}
$$

is not meromorphic in a neighborhood of the origin.

Our article is devoted to correcting the relation (1) and some of its consequences. Note that this result is related to the study of a generalized zeta-function constructed by zeros of some entire function.

\footnotetext{
*kuzovatov@yandex.ru

†AKytmanov@sfu-kras.ru

¥sadullaev@mail.ru

(C) Siberian Federal University. All rights reserved
} 


\section{Auxiliary results}

Let $f(z)$ be an entire function of order $\rho$ in $\mathbb{C}$. Consider the equation

$$
f(z)=0 .
$$

Denote by $N_{f}=f^{-1}(0)$ the set of all solutions to (2) (we take every zero as many times as its multiplicity). The numbers of roots is at most countable.

The zeta-function $\zeta_{f}(s)$ of Eq. (2) is defined in the following way:

$$
\zeta_{f}(s)=\sum_{z_{n} \in N_{f}}\left(-z_{n}\right)^{-s},
$$

where $s \in \mathbb{C}$.

In [2], using the residue theory, V.I. Kuzovatov and A. A. Kytmanov obtained two integral representation for the zeta-function constructed by zeros of an entire function of finite order on the complex plane. With the help of these representations, they described a domain which the zeta-function can be extended to.

Theorem $1.1([2])$. Let $f(z)$ be an entire function of the zero order in $\mathbb{C}$ and satisfy the condition

$$
\frac{f^{\prime}(z)}{f(z)}-\omega_{0}=O\left(\frac{1}{|z|}\right), \quad|z| \rightarrow \infty .
$$

Suppose that $0<\operatorname{Re} s<1$. Then

$$
\zeta_{f}(s)=\frac{\sin \pi s}{\pi} \int_{0}^{\infty}\left(\frac{f^{\prime}(x)}{f(x)}-\omega_{0}\right) x^{-s} d x
$$

where $\omega_{0}$ is the limit value of $\frac{f^{\prime}(x)}{f(x)}$ at infinity.

The method of proof of Theorem 1.1 shows that the statement remains valid in the case when $f(z)$ is an entire function of order less than 1 .

Now we will give an integral representation for the zeta-function $\zeta_{f}(s)$ of zeros $z_{n}$ of $f$ which are $z_{n}=-q_{n}+i s_{n}, q_{n}>0$. Let us denote

$$
F(f, x)=\sum_{n=1}^{\infty} e^{z_{n} x}
$$

We will assume that $\operatorname{Res}=\sigma>1$ and the following conditions hold:

$$
\begin{aligned}
& \varliminf_{n \rightarrow \infty} \frac{q_{n}}{n}>0, \\
& \text { the series } \sum_{n=1}^{\infty}\left(\frac{1}{q_{n}}\right)^{\sigma-1} \text { converges. }
\end{aligned}
$$

For the convergence of the series (4), using condition (5), it is necessary and sufficient (for real $x$ ) that $x>0[2]$.

Theorem 1.2 ([2]). Suppose that the conditions (5) and (6) are satisfied and Res $>1$. Then

$$
\zeta_{f}(s)=\frac{1}{\Gamma(s)} \int_{0}^{\infty} x^{s-1} F(f, x) d x,
$$

where $F(f, x)$ is defined by formula (4), and $\Gamma(s)$ is the Euler gamma-function. 
Our goal is to obtain an explicit expression for the kernel of the integral representation (3) in case $z_{n}=-\pi n^{2}$. This choice of zeros $z_{n}$ is due to the fact that for series

$$
F(f, x)=\sum_{n=1}^{\infty} e^{z_{n} x}=\sum_{n=1}^{\infty} e^{-\pi n^{2} x}:=\psi(x)
$$

for $x>0$ it is known (see, for example, [3, Chapter II, S. 6]) that

$$
2 \psi(x)+1=\frac{1}{\sqrt{x}}\left\{2 \psi\left(\frac{1}{x}\right)+1\right\} .
$$

\section{The main result}

Theorem 2.1. Let $f(z)$ be an entire function of order $\rho<1$ with zeros $z_{n}=-\pi n^{2}$. Then for real $x \in(0 ;+\infty)$ the following holds

$$
\frac{f^{\prime}(x)}{f(x)}=\frac{\sqrt{\pi}}{2 \sqrt{x}} \operatorname{cth} \sqrt{\pi x}-\frac{1}{2 x} .
$$

Proof. Since the order of $f$ is less than 1, it has the form

$$
f(z)=C \prod_{n=1}^{\infty}\left(1-\frac{z}{z_{n}}\right)
$$

The representation (7) is true, for example, for entire functions of order less than 1 or for entire functions of the first order with the additional condition, i.e. the series $\sum_{n=1}^{\infty} \frac{1}{\left|z_{n}\right|}$ is convergent. In particular, the representation (7) is true for functions of the zero genus.

It is easy to show that in this case we obtain

$$
\frac{f^{\prime}(z)}{f(z)}=\sum_{n=1}^{\infty} \frac{1}{z-z_{n}}
$$

if $z \neq z_{n}$.

Since the order of the canonical product (7) is equal to the index of convergence $\rho_{1}$ of its zeros and for given values of $z_{n}$

$$
\rho_{1}=\varlimsup_{n \rightarrow \infty} \frac{\ln n}{\ln \left|z_{n}\right|}=\frac{1}{2},
$$

representations (7) and (8) are true for considered function $f(z)$.

To further prove the assertion of the theorem, we use the standard decomposition (see, for example, [4, formula 5.1.25.4])

$$
\sum_{k=0}^{\infty} \frac{1}{k^{2}+a^{2}}=\frac{1}{2 a^{2}}+\frac{\pi}{2 a} \operatorname{cth} \pi a .
$$

Then

$$
\sum_{k=1}^{\infty} \frac{1}{k^{2}+a^{2}}=-\frac{1}{2 a^{2}}+\frac{\pi}{2 a} \operatorname{cth} \pi a .
$$


Thus

$$
\begin{aligned}
\frac{f^{\prime}(x)}{f(x)} & =\sum_{n=1}^{\infty} \frac{1}{x+\pi n^{2}}=\frac{1}{\pi} \sum_{n=1}^{\infty} \frac{1}{n^{2}+x / \pi}=\frac{1}{\pi}\left(-\frac{1}{2 x / \pi}+\frac{\pi}{2 \sqrt{x / \pi}} \operatorname{cth} \pi \sqrt{x / \pi}\right)= \\
& =-\frac{1}{2 x}+\frac{\sqrt{\pi}}{2 \sqrt{x}} \operatorname{cth} \sqrt{\pi x} .
\end{aligned}
$$

Corollary 1. Suppose that the conditions of Theorem 2.1 are satisfied. If $\omega_{0}$ is the limit value of $\frac{f^{\prime}(x)}{f(x)}$ at infinity, i.e.

$$
\omega_{0}=\lim _{x \rightarrow+\infty} \frac{f^{\prime}(x)}{f(x)}
$$

then $\omega_{0}=0$.

Proof. To prove the statement, we note that

$$
\lim _{x \rightarrow+\infty} \operatorname{cth} x=\lim _{x \rightarrow+\infty} \frac{e^{x}+e^{-x}}{e^{x}-e^{-x}}=\lim _{x \rightarrow+\infty} \frac{e^{x}\left(1+e^{-2 x}\right)}{e^{x}\left(1-e^{-2 x}\right)}=1 .
$$

Remark 1. If $f$ is an arbitrary entire function of order $1 \leqslant \rho<\infty$, with zeros $z_{n}=-\pi n^{2}$, then the ratio can be represented as

$$
\frac{f(z)}{\prod_{n=1}^{\infty}\left(1-\frac{z}{z_{n}}\right)}=e^{g(z)},
$$

where $g(z)$ is an entire function. Since $1 \leqslant \rho<\infty, g(z)$ is a polynomial, $\operatorname{deg} g=\rho$, and $\rho \in \mathbb{N}[5]$. Therefore,

$$
f(z)=\Pi(z) e^{g(z)}, \quad \Pi(z)=\prod_{n=1}^{\infty}\left(1-\frac{z}{z_{n}}\right),
$$

and

$$
\frac{f^{\prime}(z)}{f(z)}=\frac{\Pi^{\prime}(z) e^{g(z)}+\Pi(z) e^{g(z)} g^{\prime}(z)}{\Pi(z) e^{g(z)}}=\frac{\Pi^{\prime}(z)}{\Pi(z)}+g^{\prime}(z) .
$$

Consequently in this case we take

$$
\frac{f^{\prime}(x)}{f(x)}=\frac{\sqrt{\pi}}{2 \sqrt{x}} \operatorname{cth} \sqrt{\pi x}-\frac{1}{2 x}+g^{\prime}(x), \quad 1 \leqslant \rho<\infty .
$$

The first author was supported by RFBR, Krasnoyarsk Territory and Krasnoyarsk Regional Fund of Science (project number 20-41-243002). The second author is supported by the Krasnoyarsk Mathematical Center and financed by the Ministry of Science and Higher Education of the Russian Federation in the framework of the establishment and development of regional Centers for Mathematics Research and Education (Agreement No. 075-02-2021-1388).

\section{References}

[1] V.I.Kuzovatov, A.M.Kytmanov, A.Sadullaev, On the Application of the Plan Formula to the Study of the Zeta-Function of Zeros of Entire Function, J. Siberian Federal Univ. Math. Phys., 13(2020), no. 2, 135-140. DOI: 10.17516/1997-1397-2020-13-2-135-140 
[2] V.I.Kuzovatov, A.A.Kytmanov, On the Zeta-Function of Zeros of Some Class of Entire Functions, J. Siberian Federal Univ. Math. Phys., 7(2014), no. 4, 489-499.

[3] E.C.Titchmarsh, The Theory of the Riemann Zeta-Function, Oxford University Press, Oxford, 1951.

[4] A.P.Prudnikov, Yu.A.Brychkov, O.I Marichev, Integrals and series. Elementary functions, Gordon \& Breach Science Publishers, New York, 1986.

[5] A.Sadullaev, On the canonical decomposition of entire functions, Theory of functions, functional analysis and their applications, (1974), no. 21, 107-121.

\section{О дзета-функции нулей целой функции}

Вячеслав И. Кузоватов Александр М. Кытманов

Сибирский федеральный университет Красноярск, Российская Федерация

Азимбай Садуллаев

Национальный университет Узбекистана Ташкент, Узбекистан

\footnotetext{
Аннотация. Данная статья посвящена исследованию свойств дзета-функции нулей целой функции. Получено явное выражение для ядра интегрального представления дзета-функции в одном случае.
}

Ключевые слова: дзета-функция нулей, интегральное представление, каноническое произведение. 